Available online at https://jurnal.stmikroyal.ac.id/index.php/jurdimas

\title{
PENGARUH TEKNOLOGI DAN MOTIVASI TERHADAP KINERJA ANGGOTA KEPOLISIAN DI POLSEK PORSEA
}

\author{
Muhammad Amin ${ }^{1}$, Uswatun Hasanah ${ }^{2}$, Muhammad Sabir Ramadhan ${ }^{3}$ \\ ${ }^{1}$ Program Studi Sistem Komputer, STMIK Royal Kisaran \\ ${ }^{2}$ Program Studi Sistem Informasi, STMIK Royal Kisaran \\ ${ }^{3}$ Fakultas Teknik dan Prodi Teknik Informatika, Universitas Asahan \\ email: stmikroyal13@gmail.com
}

\begin{abstract}
Abstrack : Community service activities that use technology and the motivation of members of the Porsea Sector Police support the knowledge and understanding needed to produce new knowledge with current developing technology. Regarding the target in community service activities is to be able to add insight into new technologies and also create high work motivation. The activity of technology training and training support for members of the police officers in the criminal world is provided with lectures, video demonstration and question, and answer methods. The benefits obtained from this activity include, among others, being able to improve the performance of police officers in the knowledge of existing police technology, so that members work according to their fields and can master the technology in the police to work professionally. This proves to create a secure and conducive atmosphere for the community.
\end{abstract}

Keyword : motivation; perfomance; technology

\begin{abstract}
Abstrak : Kegiatan pengabdian kepada masyarakat berupa pelatihan pengaruh teknologi dan motivasi kinerja anggota polsek porsea ini bertujuan untuk memberikan pengetahuan dan pemahaman yang diharapkan dapat menghasilkan pengetahuan baru dengan adanya teknologi yang berkembang saat ini. Adapun sasaran dalam kegiatan pengabdian kepada masyarakat ini adalah untuk dapat menambah wawasan pengetahuan tentang hadirnya teknologi-teknologi baru dan juga menjadikan motivasi kerja yang tinggi. Kegaiatan pelatihan pengaruh teknologi dan motivasi kinerja anggota polsek porsea dalam dunia kriminal ini disajikan dengan metode ceramah, demontrasi video dan tanya jawab. Manfaat yang di peroleh dari kegiatan ini antara lain dapat meningkatkan kinerja anggota polsek porsea dalam pengetahuan teknologi yang ada kepolisian, sehingga anggota bekerja sesuai bidang dan dapat menguasai betul teknologi yang ada di kepolisian agar bekerja secara secara profesional. Ini membuktikan agar terciptalah suasana yang aman dan kondusif bagi masyarakat.
\end{abstract}

Keyword : kinerja; motivasi; teknologi 
Jurdimas (Jurnal Pengabdian Kepada Masyarakat) Royal

Vol. 3 No. 2, Juli 2020, hlm. 195 - 201

DOI: https://doi.org/10.33330/jurdimas.v3i2.483

Available online at https://jurnal.stmikroyal.ac.id/index.php/jurdimas

\section{PENDAHULUAN}

Teknologi Informasi (TI) telah berkembang dengan pesat pada saat ini. Teknologi Informasi adalah suatu teknologi yang digunakan untuk mengolah data, termasuk memproses, mendapatkan, menyusun, menyimpan, manipulasi data dalam berbagai cara untuk menghasilkan informasi yang berkualitas, yaitu informasi yang relevan, akurat dan tepat waktu, juga dapat digunakan untuk keperluan pribadi, bisnis, dan pemerintahan yang merupakan informasi yang strategis untuk pengambilan keputusan. (Muzakki, Susilo, and Yuniarto, 2014). Hal ini dijelaskan bahwa teknologi informasi merupakan suatu gabungan antara teknologi komputer dan teknologi komunikasi.

Polisi Republik Indonesia merupakan alat negara dan penegak hukum yang ada di suatu negara dimana didalamnya menjalankan kewajiban untuk dapat membantu masyarakat yang selalu membutuhkan, serta untuk menunjang segala aktivitas tersebut diperlukan teknologi dan informasi(Lubis, Aulia, and Yuma 2019). Peranan teknologi adalah upaya dalam melakukan segala kegiatan yang menjadi tanggung jawab organisasi sebuah institusi kepolisian dalam melakukan pekerjaannya agar dapat mengambil tindakan-tindakan dalam memutuskan suatu perkara. Supaya penggunaan sistem dan teknologi informasi dapat berguna bagi user nya dan mambantu pekerjaan dengan terstruktur, oleh karena itu setiap pelaku usaha harus mampu meningkatkan kompetensinya (Sadewa and Siahaan, 2016).
Untuk menunjang kinerja kepolisian diperlukan teknologi yang dinamakan dalam kepolisian divisi telematika Polri, tugas dari divisi tersebut berkaitan dalam bidang teknologi. Pengelolaan pemahaman pegawai kepolisian yang baik merupakan kunci sukses untuk mencapai tujuan suatu organisasi.

Ada 5 indikator untuk mengukur kinerja karyawan secara individu yaitu: Kualitas, Kuantitas, Ketepatan waktu, Efektivitas dan Kemandirian. Oleh karena itu teknologi informasi khususnya di jaringan nirkabel atau umum disebut internet of things, atau dikenal juga dengan singkatan' IoT, merupakan sebuah konsep yang bertujuan untuk memperluas manfaat dari konektivitas internet yang tersambung secara terus-menerus (Ananda and Amin, 2019).

Dalam kegiataanya setiap pegawai polri harus memiliki keinginan yang tinggi dalam menjalankan tugasnya dan segala kegiatannya karena motivasi dapat menjadi penggerak semangat yang sangat mempengaruhi kinerja individu yang di dukung dengan pemahaman teknologi yang kuat. Motivasi merupakan suatu proses yang mana dimulai dari defisiensi fisiologis yang menggerakkan perilaku setiap individu yang memiliki tujuan (Jaya and Ningsih, 2018). Tujuan dilakukannya kegiatan ini untuk mengetahui sejauh mana pengaruh teknologi dan motivasi terhadap kinerja anggota Kepolisian di Polsek Porsea dalam melayani masyarakat yang sering melaporkan segala masalah yang di hadapi. 
Jurdimas (Jurnal Pengabdian Kepada Masyarakat) Royal

Vol. 3 No. 2, Juli 2020, hlm. 195 - 201

DOI: https://doi.org/10.33330/jurdimas.v3i2.483

Available online at https://jurnal.stmikroyal.ac.id/index.php/jurdimas

\section{METODE}

Metode pelaksanaan dalam pengabdian masyarakat ini adalah bentuk pelatihan di aula polsek dengan metode ceramah, diskusi dan tanya jawab. Kegiatan ini di ikuti seluruh anggota kepolisian Polsek Porsea. Adapun tahapan dalam kegiatan pengabdian kepada masyarakat ini diawali dengan mempersiapkan materi yang akan diberikan, seperti slide presentasi dan alat peraga lainnya. Memastikan tempat dan fasilitas pendukung seperti projector, dan kebutuhan lainnya pada saat kegiatan akan dilangsungkan. Serta menjelaskan teori tentang pengaruh teknologi dan motivasi terhadap kinerja.

\section{PEMBAHASAN}

\section{Pengenalan Teknologi di Kepolisian Pembacaan Sidik Jari}

Sidik Jari adalah suatu data diri seseorang yang tidak akan mungkin bisa sama dengan orang lain di dalam kehidupan ini. Karena keunikannya dan kekhasan dari bentuk pola jari yang masing-masing seseorang memilikinya, sidik jari digunakan dalam berbagai kondisi dan keadaan, seperti yang dilakukan oleh pihak kepolisian dalam penyelidikan suatu kasus kejahatan.

$$
\text { Adapun dalam menentukan }
$$
tindakan kejahatan yang terjadi seperti pembunuhan, perampokan dan pemerkosaan di kepolisisan terdapat 2 alat deteksi yang dapat digunakan yaitu:

1) Fingerprint Scanner

Fingerprint Scanner adalah suatu sistem yang memiliki dua kegunaan yaitu berfungsi sebagai pengambil gambar sidik jari seseorang dan dapat melihat pola alur kesesuaian sidik jari dari gambar yang di dapat di tempat kejadian dengan pola alur sidik jari yang tersedia di sistem database.

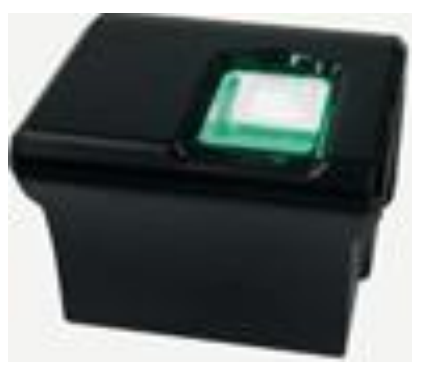

Gambar 1. Fingerprint Scanner

\section{2) Fingerprint Reader}

Fingerprint reader adalah suatu alat pembaca kesamaan sidik jari seseorang. Adapun hasil yang di keluarkan dari pembacaan sidik jari tersebut berupa sebuah gambar dimana bentuk sidik jari orang ke orang berikutnya pastilah berbeda satu sama lain. Ini merupakan alat yang lebih mudah digunakan dan dapat di bawa kemana saja dikarenakan bentuk yang lebih kecil.

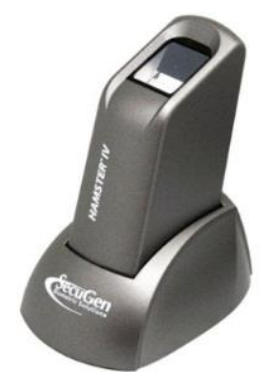

Gambar 2. Fingerprint Reader 
Jurdimas (Jurnal Pengabdian Kepada Masyarakat) Royal

Vol. 3 No. 2, Juli 2020, hlm. 195 - 201

DOI: https://doi.org/10.33330/jurdimas.v3i2.483

ISSN 2622-3813 (Online)

Available online at https://jurnal.stmikroyal.ac.id/index.php/jurdimas

\section{Robot Penjinak BOM}

Sebagaimana kita ketahui salah satu teknologi terbaru yang digunakan saat ini yaitu Mobil Robot Penjinak Bom LIPI (MOROLIPI) yang diproduksi oleh Pusat Penelitian Tenaga Listrik dan Mekatronik LIPI. MOROLIPI adalah sebuah mobil robot penjinak yang tidak sekedar dapat berjalan di medan yang bergelombang dan terjal. Dimana kedepannya peralatan ini akan dipersiapkan sebagai mobil robot yang diperhitungkan dalam kategori peralatan militer yang akan ambil andil di garda terdepan pada saat terjadi pertempuran di medan perang.

Tidak itu saja kegunaan dari mobil robot ini, dapat juga diguanakan sebagai robot pengintai dalam membantu pasukan anti huru-hara untuk mengatasi kerusuhan yang terjadi. Sebagaimana kita ketahui mobil robot ini dioperasikan dari jarak jauh menggunakan joystick sebagai remote control untuk dipakai pada saat menjinakkan bom dengan cara memotong kabel yang manjadi rangkaian aliran pemicu ledakan bom.

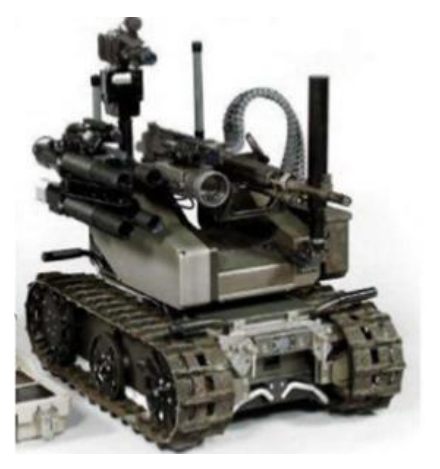

Gambar 3. Robot Penjinak Bom

\section{Pengertian Motivasi}

Motivasi merupakan perubahan energi dalam diri seseorang yang di tandai dengan timbulnya perasaan dan reaksi untuk mencapai tujuan. Definisi tersebut menunjukan bahwa motivasi merupakan suatu yang kompleks sebagai suatu energi penggerak dan pengarah yang dapat memperkuat dan mendorong seseorang untuk bertingkah laku. Motivasi juga dapat diartikan sebagai kondisi atau energi yang menggerakan diri pegawai yang terarah atau tertuju untuk mencapai tujuan organisasi perusahaan (Wenty, 2015)

Dimana dengan memberikan pemahaman seperti itu bertujuan agar dapat mengingatkan pegawai untuk lebih semangat dalam mencapai hasil sebagaimana dikehendaki dari orangorang tersebut. Motivasi dapat berupa motivasi intrinsik dan motivasi ekstrinsik.

\section{Kinerja}

Perstasi yang dapat dicapai oleh seseorang atau sekelompok orang dalam suatu organisasi, sesuai dengan wewenang dan tanggung jawab masingmasing dalam rangka upaya mencapai tujuan organisasi bersangkutan secara legal tidak melanggar hukum dan sesuai dengan moral dan etika (Andriana, Sumarlin, and Panjaitan, 2020). Kinerja pegawai dapat diukur melalui jumlah pekerjaan, kualitas pekerjaan, ketepatan waktu, kehadiran, kemampuan kerjasama. Adapun hasil dari kinerja seorang pegawai akan terlihat dari usaha yang dilakukannya dalam melakukan pekerjaan, ini tidak terlepas dari keinginan yang kuat untuk menghasilkan sesuatu yang bermanfaat, untuk dapat menaikkan tingkatan jabatan dalam posisi pekerjaan. 
Jurdimas (Jurnal Pengabdian Kepada Masyarakat) Royal

Vol. 3 No. 2, Juli 2020, hlm. 195 - 201

DOI: https://doi.org/10.33330/jurdimas.v3i2.483

Available online at https://jurnal.stmikroyal.ac.id/index.php/jurdimas

\section{Hubungan Motivasi Dengan Kinerja}

Motivasi dapat terbentuk dari sikap pegawai jika yang bersangkutan sedang di hadapi pada masalah. Penilaian kinerja merupakan kegiatan yang mutlak harus dilakukan untuk mengetahui prestasi yang dapat dicapai setiap karyawan (Jaya and Ningsih, 2018). Sikap mental yang besar pada diri seorang pegawai akan mendorong selalu berpikir positif setiap kondisi kerja agar semakin memperkokoh hubungan dengan motivasi kerja.

Penilaian kinerja (performance appraisal) merupakan proses yang digunakan perusahaan untuk mengevaluasi job performance (Bilgah, 2018). Oleh sebab itu, terdapat aspek yang mempengaruhi motivasi kerja pegawai, seperti rasa aman dalam bekerja, gaji yang sesuai kinerja, kondisi sekitar tempat kerja yang nyaman, reward atas kinerja yang baik dan persamaan perlakuan dari pimpinan.

\section{Variabel}

Variabel sebagai salah satu objek yang ditentukan oleh peneliti dengan tujuan untuk memperoleh hasil informasi yang dapat disimpulkan. Adapun tabel di bawah ini menjadi indikator dalam melihat motivasi kerja anggota polsek porsea.
Tabel 1. Indikator Variabel

\begin{tabular}{ccc}
\hline No & $\begin{array}{c}\text { Motivasi } \\
\text { Kerja } \\
\text { Gaji }\end{array}$ & $\begin{array}{c}\text { Kinerja } \\
\text { Pegawai }\end{array}$ \\
\hline 1 & Kecakapan Kerja \\
\hline 2 & Bonus & Keterampilan \\
\hline 3 & $\begin{array}{c}\text { Peraturan dan } \\
\text { Sanksi }\end{array}$ & $\begin{array}{c}\text { Tingkat } \\
\text { Kesungguhan }\end{array}$ \\
\hline 4 & $\begin{array}{c}\text { Apresiasi } \\
\text { Kerja }\end{array}$ & $\begin{array}{c}\text { Tingkat } \\
\text { Kesehatan }\end{array}$ \\
\hline 5 & Fasilitas Kerja & Tanggung Jawab \\
\hline 6 & $\begin{array}{c}\text { Mekanisme } \\
\text { Penilaian } \\
\text { Kerja }\end{array}$ & Ketaatan \\
\hline 7 & $\begin{array}{c}\text { Kerjasama } \\
\text { Tim }\end{array}$ & $\begin{array}{c}\text { Ketepatan Waktu } \\
\text { Pengambilan } \\
\text { Keputusan }\end{array}$ \\
\hline 8 & $\begin{array}{c}\text { Promosi } \\
\text { Jabatan }\end{array}$ & $\begin{array}{c}\text { Kebebasan } \\
\text { Berbendapat }\end{array}$ \\
\hline 9 & Demosi & $\begin{array}{c}\text { Pendidikan dan } \\
\text { Pelatihan }\end{array}$ \\
\hline 10 & $\begin{array}{c}\text { Lingkungan } \\
\text { Kerja }\end{array}$
\end{tabular}

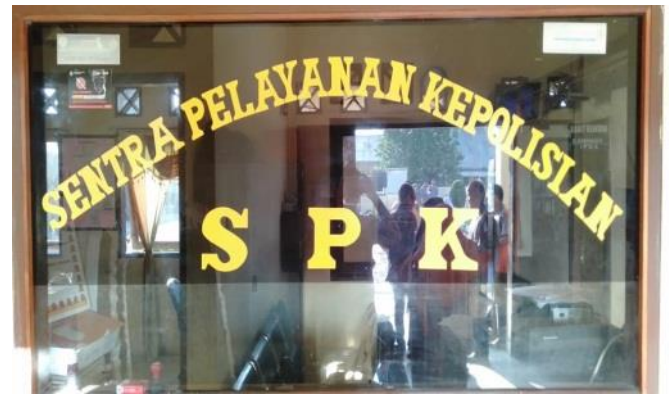

Gambar 1. Sentra Pelayanan Kepolisian

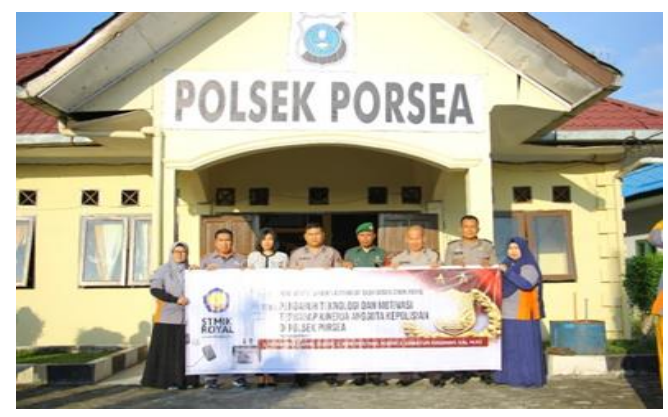

Gambar 2. Foto Bersama Dengan Jajaran Pimpinan Polsek Porsea. 
Jurdimas (Jurnal Pengabdian Kepada Masyarakat) Royal

Vol. 3 No. 2, Juli 2020, hlm. 195 - 201

DOI: https://doi.org/10.33330/jurdimas.v3i2.483

ISSN 2622-3813 (Online)

Available online at https://jurnal.stmikroyal.ac.id/index.php/jurdimas

\section{UCAPAN TERIMA KASIH}

Ucapkan terima kasih kepada Bapak Anda Putra Lubis, SE, MMA. Selaku Ketua Yayasan Pendidikan Royal Teladan Asahan, Bapak AKP. Napsanto, SH. Selaku Kapolsek Porsea. Para Jajaran Polsek Porsea, Tim pengabdian kepada masyarakat yang telah bekerjasama dengan baik, sehingga kegiatan ini dapat berjalan dengan lancar

\section{SIMPULAN}

Berdasarkan kegiatan pengabdian kepada masyarakat di polsek porsea, maka di dapatkan hasil pengaruh teknologi dan motivasi kinerja anggota polsek porsea di pengaruhi oleh variabel-variabel gaji, kecakapan kerja, bonus, keterampilan, apresiasi kerja, tingkat kesehatan, fasilitas kerja, tanggung jawab, kerja tim, ketepatan waktu, promosi jabatan dan pengambilan keputusan. Itu semua menjadi tolak ukur dalam bekerja, disamping motivasi yang tinggi baik dari teman sejawat maupun atasan, sebagaimana terlihat dari tanggapan responden mengenai variabel kinerja mendapatkan persentase nilai sebesar $87 \%$ yang termasuk dalam kategori sangat tinggi.

\section{DAFTAR PUSTAKA}

Ananda, Ricki, and Muhammad Amin. 2019.

"WORKSHOP

PELATIHAN PERANCANGAN

INTERNET OF THINGS

BERBASIS ARDUINO UNO

JENIS R3 / R3 SMD DI SMK

SWASTA KARYA."

Jurdimas(Jurnal Pengabdian

Kepada Masyarakat)Royal

2(2):121-26.

Andriana, Myra, Tantiek Sumarlin, and

Roymon Panjaitan. 2020.

"Pengaruh Teknologi Informasi

Dan Sistem Informasi Perpajakan

Terhadap Kinerja Manajerial

Keuangan." Jesya (Jurnal

Ekonomi \& Ekonomi Syariah) 3(1):74-83.

Bilgah. 2018. "Pengaruh Penilaian Kinerja Terhadap Motivasi Kerja Pegawai Pada PT Astra International Jakarta Utara." Cakrawala 18(2):213-20.

Jaya, Indra, and Surya Ningsih. 2018. "Hubungan Motivasi Kerja Dengan Kinerja Karyawan Pada Pt Kao Indonesia." JIMFE (Jurnal Ilmiah Manajemen Fakultas Ekonomi) 2(1):20-29.

Lubis, Iin Almeina, Romy Aulia, and Febby Madonna Yuma. 2019. "PENINGKATAN

PEMANFATAN PERAN

TEKNOLOGI INFORMASI

BAGI MASYARAKAT

SEKITAR POLSEK PORSEA

KAB . TOBA SAMOSIR

PENDAHULUAN."

Jurdimas(Jurnal Pengabdian

Kepada Masyarakat)Royal 2(2):177-80.

Muzakki, Mukhammad Hilmi, Heru Susilo, and Saiful Rahman Yuniarto. 2014. "Pengaruh Penggunaan Teknologi Informasi Terhadap Kinerja Karyawan (Studi Pada Karyawan PT. TELKOM Pusat Divisi Regional V Surabaya)." Jurnal 
Jurdimas (Jurnal Pengabdian Kepada Masyarakat) Royal

Vol. 3 No. 2, Juli 2020, hlm. 195 - 201

ISSN 2614-7912 (Print)

DOI: https://doi.org/10.33330/jurdimas.v3i2.483

ISSN 2622-3813 (Online)

Available online at https://jurnal.stmikroyal.ac.id/index.php/jurdimas

Administrasi Bisnis $\quad(J A B)$ 39(2):169-75.

Sadewa, Ifan, and Kondar Siahaan. 2016. "Analisis Dan Perancangan Sistem Indormasi Unit Kegiatan Mahasiswa (UKM) Berbasis Web Pada Universitas Batanghari." Jurnal Manajemen Sistem
Informasi 2(1):135-46.

Wenty, Cici Syafri. 2015. "Hubunganmotivasi Kerja Dengan Kinerja Pegawai Dinas Pendidikan Kabupaten Pesisir Selatan." Jurnal Administrasi Pendidikan 3(2):937-42. 